\title{
Toying With a Ridiculous Material
}

The shortage of natural rubber during the Second World War prompted research for alternatives. Substituting silicon for carbon-the backbone of natural rubber chains-quickly became a major line of investigation, but it would take years of research to produce usable silicone rubber materials. Along the way, groups at both the Mellon Institute in Pittsburgh, Pennsylvania (through a fellowship sponsored by Dow Corning) and General Electric in New Haven, Connecticut, accidentally stumbled across a novel material that has fascinated generations of children and adults and started perhaps the silliest debate in the history of science: Who invented Silly Putty?

The official line is that in 1943 James Wright, an engineer working in General Electric's New Haven laboratories, accidentally put a drop of boric acid into silicone oil, and found that the resultant gooey material bounced when he threw it on the floor. It also stretched more than natural rubber. After experimenting with various compositions, Wright applied for a patent on a "Process for Making Puttylike Elastic Plastic, Siloxane Derivative Composition Containing Zinc Hydroxide" on December 23, 1944; he was awarded U.S. Patent Number 2,541,851 on February 13, 1951.

However, Earl L. Warrick and Rob Roy McGregor at Mellon Institute, working for Dow Corning, may have a better claim to the invention. They were experimenting with ways to make polydimethylsiloxane (PDMS) fluids more viscous. At some point, they, too, added boric acid to the mix, with the same results. As Warrick recalled in his memoir Forty Years of Firsts: The Recollections of a Dow Corning Pioneer, "By late summer 1940 we knew how to carry fluids to a 'gummy' or rubbery state, but we still had not developed a silicone rubber. One of our attempts produced instead a curiously resilient material which we called 'bouncing putty.' We knew the substance was not the polymer we were looking for, but we added fillers to it and took advantage of its unique properties to astound visitors by bouncing it off the ceilings and walls of our laboratories."

They applied for a patent on March 30, 1943, for "Treating Dimethyl Silicone Polymer with Boric Oxide," and were awarded U.S. Patent Number 2,431,878 on December 2, 1947. So, if Warrick's memory is correct, he and McGregor invented bouncing putty three years before Wright. The patent filing and award dates favor them, also.

Whether either group knew what the other had created is not known, but it made little difference because "no use was apparent at the time," as Warrick wrote. What is not in dispute is that a unique material had been born. According to the official Web site (www.sillyputty.com), it has many interesting properties: "It stretches without breaking, yet it can be 'snapped off' cleanly. It bounces higher than a rubber ball. It floats if you shape it in a certain way, yet sinks in others. It can pick up pencil marks from pages and comics from some newspapers. If you slam it with a hammer, it keeps its shape, yet if you push with light, even pressure, it will flatten with ease." More technically, according to Chemical \& Engineering News, "Silly Putty is a dilatant compound, which means it has an inverse thixotropy-that is, as a viscous suspension or gel, it becomes solid under the influence of pressure."

\section{"Apollo 8 astronauts took Silly \\ Putty to the moon... to stick tools to the spacecraft's walls."}

Warrick and McGregor abandoned the material after obtaining the patent, but General Electric put some effort into finding possible applications. In the November 25, 1944, "Talk of the Town" section of the New Yorker magazine, a correspondent described a cocktail party thrown by General Electric at a New York Engineers' Club to introduce their bouncing putty to the press. Each attendee received a ball of what they now were calling "nutty putty" and a scotch and soda, which led to predictable high-jinks, including draping a General Electric chemist with stretched ribbons of the putty. A public relations agent present proclaimed silicone to be the "eighth wonder of the world." In 1945 in an effort to drum up ideas, the company also sent samples to engineers worldwide. The preoccupation of these engineers with finding some useful application for this strange material often brought their other work to a complete halt, and in every case was of no avail

Finally, according to one version of the story, an unemployed advertising man named Peter Hodgson discovered nutty putty at a party in 1949 and saw its possibility as a novelty toy. He purchased the rights to the product from General Electric, renamed it Silly Putty, started packaging it in plastic eggs as an Easter promotion, and convinced the owners of Nieman-Marcus and Doubleday Bookstores to carry the product. The New Yorker published another piece in the August 26, 1950 issue describing a reporter's visit to a Doubleday Bookstore. The owner of the store announced sales of 10,000 eggs of Silly Putty in the past month, mostly to adults claiming it was for their children. Hodgson agreed that the product was mostly for adults: "It means five minutes of escape from neurosis," Hodgson said. "The inherent ridiculousness of the material acts as an emotional release to hard-pressed adults." He also noted that it was excellent for cleaning ink out of dirty typewriter keys. The New Yorker article resulted in orders for a quarter million eggs in just over three days.

Hodgson died in 1976 with an estate worth $\$ 140$ million, but by then his product had achieved popularity around the world —and beyond. In 1968, the Apollo 8 astronauts took Silly Putty to the moon, using it as a stress reliever and to stick tools to the spacecraft's walls. In 1977, Binney \& Smith, manufacturer of Crayola Crayons, bought Silly Putty and continue to market it today. In 2000, to celebrate the 50th anniversary of this novelty, the Smithsonian Institution put vintage eggs of Silly Putty into its "Material World" display of significant materials that have shaped American culture. Ironically, though Wright's General Electric product evolved into the original Silly Putty, the raw material for Silly Putty has been made since 1959 by Warrick and McGregor's Dow Corning Corporation disguised under the product name 3179 Dilatant Compound.

TIM PALUCKA

FOR FurTher READING: Earl L. Warrick, Forty Years of Firsts: The Recollections of a Dow Corning Pioneer. (McGraw-Hill Publishing Company, New York, 1990), pp. 27-28, 176; Ann Thayer, "What's That Stuff? Silly Putty," Chemical \& Engineering News, 78 (48) (November 27, 2000), p. 27; "Silicone" in the New Yorker, XX (41) (November 25, 1944), pp. 18-19, author unidentified; "Here to Stay" in the New Yorker, XXVI (27) (August 26, 1950), pp. 19-20, author unidentified; "Silly Putty University," Binney \& Smith's Official Web site, www.sillyputty.com (accessed February 2007). 